\title{
Erratum to: cGAS-STING Activation in the Tumor Microenvironment and Its Role in Cancer Immunity
}

\author{
Geneviève Pépin and Michael P. Gantier
}

Erratum to:

Chapter 8 in: D. Xu (ed.), Regulation of Inflammatory

Signaling in Health and Disease, Advances in Experimental Medicine and Biology 1024, https://doi.org/10.1007/978-981-10-5987-2_8

The original version of this chapter was revised to include the following references:

40. Baird JR, Friedman D, Cottam B, Dubensky TW Jr, Kanne DB, Bambina S, Bahjat K, Crittenden MR Gough MJ (2016) Radiotherapy combined with novel STING-targeting oligonucleotides results in regression of established tumors. Cancer Res 76(1):50-61. https://doi. org/10.1158/0008-5472.CAN-14-3619

41. Li T, Cheng H, Yuan H, Xu Q, Shu C, Zhang Y, Xu P, Tan J, Rui Y, Li P, Tan X (2016) Antitumor activity of cGAMP via stimulation of cGAS-cGAMP-STING-IRF3 mediated innate immune response. Sci Rep 6:19049. https://doi.org/10.1038/srep19049

The updated online version of this chapter can be found at https://doi.org/10.1007/978-981-10-5987-2_8 